\title{
Relações customizadas e o ideário de amor na contemporaneidade
}

\author{
Ana Nascimento de Amorim \\ Centro Universitário Newton Paiva \\ Márcia Stengel \\ Pontifícia Universidade Católica de Minas Gerais
}

\begin{abstract}
Resumo
A regra pós-moderna sugere ausência de discursos e práticas normatizadores, apontando ser possível a homens e mulheres não somente reproduzir modelos sociais, mas inventar formas de parcerias amorosas, o que chamamos de customizar as relações. Consideramos a diversidade das configurações conjugais coexistentes em nossa sociedade e a família moderna que permanece como modelo ideal para a maioria. A partir destas considerações, discutimos em que medida um casal homossexual feminino e um heterossexual das camadas médias de Belo Horizonte estariam repetindo valores mais próximos do modelo conjugal moderno e do ideário romântico, e/ou reinventando formas. Concluímos que a combinação dos ideais e valores assumidos pelos casais não só reflete a ideia de customização, pois cada casal assume um modo singular de se relacionar, como diz também de uma capacidade adaptativa aos nossos tempos.
\end{abstract}

Palavras-chave: conjugalidade; ideal de amor; amor romântico; amor confluente; contemporaneidade.

\begin{abstract}
Customized relations and the ideal of love in the contemporaneity. The postmodern rule suggests absence of norms, practices and discourses pointing possible men and women not only reproduce social models, but invent ways of loving partnerships, what we call customizing relationships. We consider the diversity of coexisting conjugal settings in our society and the modern family that remains as ideal model for most. From these considerations, we discussed the extent to which a homosexual couple and a heterosexual Belo Horizonte medium layers were repeating values closer to the model of the modern romantic ideal marital, and/or reinventing ways. We discussed the extent to which couples would be repeating values closer to the model of the modern romantic ideal marital, and/or reinventing ways. We conclude that the combination of the ideals and values assumed by married couples not only reflects the idea of customization, because every couple takes a singular way to relate, as also an adaptive capacity to our time.
\end{abstract}

Keywords: conjugality; ideal of love; romantic love; confluent love; contemporaneity.

\section{Resumen}

Relaciones personalizadas y la ideología del amor en contemporaneidade. La regla postmodernista sugiere ausencia de normas, prácticas y discursos señalando posibilidades a hombres y mujeres no sólo reproducir modelos sociales, sino inventar formas de asociaciones amorosas, lo que llamamos relaciones "customizadas". Consideramos la diversidad de configuraciones conyugales coexistentes en nuestra sociedad y la familia moderna que permanece como modelo ideal para la mayoría. De estas consideraciones, hemos hablado de la medida en que una pareja homosexual y un heterosexual de capas medianas de Belo Horizonte estaban repitiendo valores cercano al modelo del ideal romántico moderno marital, o reinventar maneras. Hablamos de la medida en que las parejas sería ser repitiendo valores más cercano al modelo del ideal romántico moderno o reinventar formas. Concluimos que la combinación de ideales y valores asumidos por las parejas no sólo refleja la idea de personalización, porque cada pareja toma una forma singular de relacionarse, como también una capacidad de adaptación a nuestros tiempos.

Palabras clave: conyugalidad; ideal del amor; amor romántico; amor confluente; contemporaneidad.

A té algumas décadas, o casamento legal e indissolúvel era a única forma aceita de legitimar as relações conjugais, sendo praticamente inconcebível pensar família e conjugalidade como distintas, já que o casamento era o único caminho possível para se estruturar uma família. A partir de 1960 muitas foram as transformações culturais e Acervo disponivel em: www.scielo.br/epsic 
científicas que geraram grande impacto sobre os modelos tradicionais de família e conjugalidade.

No cenário contemporâneo se nota uma crise psicossocial e institucional da conjugalidade, que põe em questão as formas mais tradicionais de pensar os relacionamentos (Diniz Neto \& Féres-Carneiro, 2005). Na esteira destas mudanças, diferentes formatações acabam sendo introjetadas e legitimadas social e culturalmente. Surgem as parcerias homossexuais, os relacionamentos "abertos", os casamentos não formais, as famílias encabeçadas por mulheres ou em que o pai assume o cuidado integral dos filhos, entre outras possibilidades (Matos, 2000).

Contudo, o modelo tido como padrão social e referência de uma condição estável é, ainda hoje, o da família nuclear, permanecendo como um modelo ideal para a maioria em nossa sociedade. A família nuclear moderna ou conjugal, que se solidifica no século XIX, pode ser definida como um grupo composto por um casal, unido pelo matrimônio, e um número pequeno de filhos, decorrente desta união, o que caracteriza um núcleo restrito em estrutura, função e hierarquia. Nesta configuração, a função da família centra-se na criação dos filhos por um viés afetivo (Stengel, 2004). Vale ressaltar que essa família pauta-se na lógica da heteronormatividade.

Atualmente, longe de se ter a exclusão de um modelo de família e conjugalidade precedente, o que vemos é a existência simultânea de uma série de arranjos, cujos modos de regulação variam dos mais tradicionais aos mais alternativos, com valores que ora tendem a manter padrões mais conservadores, e ora se aproximam do discurso individualista na contemporaneidade, em que se vê como fundamental a preservação da autonomia e dos interesses pessoais.

Há que se levar em conta que este cenário é acompanhado por um discurso que aponta ser possível a homens e mulheres não somente reproduzir modelos sociais, mas inventar formas de parcerias amorosas. Diante da regra pós-moderna ${ }^{1}$ que sugere a ausência de discursos e de práticas normatizadores, o indivíduo se vê, diante da oportunidade e do desafio de criar o casal, o casamento e a família que quer para si (Goldenberg, 2001; Vaitsman, 1994). É frente à alternativa de se guiar tanto por um padrão em que predominam valores modernos, quanto por padrões gestados na Pós-modernidade, que as configurações conjugais ganham o caráter de algo customizado ${ }^{2}$.

Este termo foi neste trabalho adaptado para as relações conjugais por remeter a uma ideia de personalização, sugerindo uma apropriação de diferentes ideais e valores. Nesta concepção, customizadas serão consideradas as relações que, mesmo partindo de um modelo pré-formatado, rompem em alguma medida com os estereótipos e paradigmas existentes. Nelas se combinam, em condições de adaptação pós-modernas, elementos "novos" e "antigos", em busca de formas particulares.

$\mathrm{Na}$ contemporaneidade, nota-se a contradição que ocorre entre a expectativa de vivenciar uma relação calcada no ideário romântico e as dificuldades decorrentes de não se conseguir responder a esse ideal. Tomamos o amor romântico aqui sob o ponto de vista de Costa (1998), como possuidor de uma historicidade, sendo passível de sofrer variações, ainda que seja um ideal dominante nos dias de hoje.

A partir destas considerações, pretendemos discutir neste artigo em que medida os casais heterossexuais e homossexuais estariam repetindo valores mais próximos de um padrão tradicional de modelo conjugal moderno e do ideário romântico, e/ou reinventando formas, em acordo com a ideia de customização que adotamos. Propomos, portanto, uma revisão das formas contemporâneas de vivência das conjugalidades, adotando como referência o amor romântico.

No que tange aos relacionamentos homossexuais, vale ressaltar que comumente são enquadrados no modelo heteronormativo vigente. Como salienta Butler (2008, p. 182), “a categoria sexual é um constructo naturalizado que faz a instituição da heterossexualidade normativa parecer inevitável.". Estudos que tratam das especificidades da homoconjugalidade, tal como os de Butler (2008) e Grossi, Uziel e Mello (2007), apontam para a necessidade de compreendermos a homoconjugalidade por uma ótica particular.

Considerando estes aspectos, é importante dizer que não nos pautamos em uma proposta que visasse salientar a especificidade da orientação sexual dos sujeitos na experiência de seus relacionamentos de uma forma dicotômica, pois nosso foco é compreender como os casais em diferentes formatações apreendem e pautam seus relacionamentos em valores modernos e pós-modernos nos dias atuais.

\section{O ideal de amor nas relações conjugais pós-moder- nas}

O amor, tido como uma sensação vívida, ora prazerosa, ora causadora de grande sofrimento, é facilmente reconhecido, em nossa sociedade ocidental, devido a uma influência do Romantismo, que o configura como uma emoção livre, marcada por uma nuance de sentimentos, em oposição a uma razão comedida. O amor é concebido como algo espontâneo e natural, o que o aproxima de um sentimento tido como universal. Esta noção nos leva a pensar que a experiência amorosa acontece de modo muito semelhante com todos nós, o que, a princípio, pode ser considerado coerente se, associando-a à capacidade de sentir, definirmos esta experiência como um impulso que primordialmente não possui fundamento para além de si mesmo, tal como afirma Simmel (2006). Este autor nos aponta uma perspectiva em que o amor é pensado como um produto subjetivo, caracterizando-o como um fenômeno possuidor de uma essência central. Aqui, interessa-nos enfatizá-lo sob um aspecto mais relativista, tomando-o como uma crença emocional, conforme propõe Costa (1998).

Este autor promove uma desconstrução das supostas naturalidade e universalidade do amor, ao propor que se trata de uma convicção, passível, como tal, de ser reformulada, conforme diferentes critérios. Para além da concepção do amor como puro sentimento, Costa (1998) lhe associa uma dimensão que é a do juízo, a da razão, colocando-o como algo opcional, e não relacionado a uma condição inerente, como se costuma crer. Ele 
não nega o impulso amoroso, mas salienta haver uma variação do que atrai ou mesmo excita, eroticamente falando, o que implica perceber que a emoção amorosa não está dissociada da vontade e de aspectos racionais, os quais, por sua vez, refletem elementos da cultura. Nas questões do amor, para além do sentimento, o autor considera os hábitos culturais, os fatores sociais, os aspectos psicológicos e outras idiossincrasias como condicionamentos que podem estar imbricados nas vivências amorosas.

Nós aprendemos que o amor é um bem desejável e, por isso, não duvidamos de sua universalidade. Entretanto, o fato é que esta última não tem nada de evidente. Na verdade, a experiência amorosa se constitui em meio a uma complexa associação de fatos e experiências emocionais passadas com aquelas vivenciadas no presente. Por exemplo, é através de histórias e romances consagrados, como o de Romeu e Julieta, que nos é transmitida uma determinada forma de sentir e pensar o amor, a qual se torna referência ao nos identificarmos com ela. É com processos como este que aprendemos uma certa noção de amor, que acaba por ser naturalizada e perpetuada. A experiência do amor, tal como a conhecemos, é algo que é ensinado e aprendido, e, portanto, varia segundo o local e a cultura em que se constrói. Daí que sua condição de universal e natural não se faz valer (Costa, 1998).

A prática amorosa evidencia não serem nossas escolhas feitas só de sentimentos. A ideia de amor desvinculado dos aparatos sociais que o restringia, própria do ideário romântico, desconsidera o fato de que a realidade social e psicológica continua tendo um peso significativo quando se trata de eleger um parceiro. É notório como os preconceitos de classe, raça, religião ou posição econômica e social limitam a escolha dos possíveis pretendentes àqueles que estão à altura de atenderem certas exigências. Como afirma Costa (1998): "O amor é seletivo como qualquer outra emoção presente em códigos de interação e vinculação interpessoais." (p. 17). O amor, como ideal, portanto, não é aleatório. Ele surge de um determinado lugar, sendo compartilhado por pessoas que se reconhecem entre si.

Procuramos enfatizar que o amor não se resume ao seu aspecto sentimental e passional, não sendo, tampouco, algo inato. Antes de tudo, importa notar que a noção de amor é contextualizada, possuindo uma historicidade, a qual a faz passível de sofrer interferências e de se transformar. Sendo congruente com este raciocínio, Chaves (2004) sustenta que a maneira como o amor é representado e as expectativas que levam uma prática amorosa a ser sentida como satisfatória caminham juntas a certas tendências que surgem ao longo do tempo, impondo suas regras e disseminando valores, ideais e modelos. Estes, quando chegam a ser considerados os mais corretos, determinam com o que o indivíduo pode ou deve vir a se identificar.

O amor romântico seria um destes modelos, surgido no final do século XVIII, com a particularidade de continuar sendo uma das marcas registradas da cultura ocidental, resistindo como uma forte referência para as práticas amorosas nos dias de hoje (Costa, 1998). Ele nasce sob a influência do Romantismo, movimento que surge na Europa nos últimos anos do século XVIII e primeiros anos do século XIX, promovendo uma verdadeira revolução de padrões culturais e humanos, em diferentes âmbitos. Seus aspectos mais evidentes eram o sentimentalismo e a valorização da singularidade, a qual deveria se manifestar através do uso da sensibilidade e da capacidade imaginativa, de forma criativa e fluida. Com isso se manifestava não só uma forte oposição à cultura da razão - típica do Iluminismo, em seu aspecto materialista e universalista -, como se evidenciava a pretensão de se promover uma ruptura com as normas tradicionais, valorizando-se a postura e o caráter contestadores (Massaud, 2002). Estimulavam-se as particularidades, em diferentes formas de expressão, valorizando-se a individualidade e uma dimensão subjetiva, que acaba por apontar para a existência de uma vida sentimental rica e variável, própria de cada um.

Influenciado pela produção literária do Romantismo, o amor romântico introduziu a ideia de uma narrativa a ser vivida entre duas pessoas que juntas poderiam construir sua própria história de maneira individualizada, sem ligação direta com os processos sociais mais amplos (Giddens, 1993). Costa (1998), a partir da leitura de Salomon, afirma que o amadurecimento do amor romântico só foi possível em função do contexto em que ele despontou. Para a sua descrição, o autor considera o momento em que houve um distanciamento da família nuclear do meio social mais abrangente, promovendo-se uma ênfase à dimensão da privacidade e das relações estabelecidas na intimidade; ressalta a concessão a homens e mulheres de certa margem de escolha pessoal na formação de parcerias conjugais, em consonância com a afirmação do individualismo; destaca a força das narrativas românticas; e, lembra a diminuição do contraste entre o amor que era praticado dentro do casamento, considerado sagrado, e aquele que se exercia fora da união formal, tido como profano.

$\mathrm{O}$ amor romântico pode ser pensado como um herdeiro de uma concepção de privacidade e de autonomia, com uma ênfase nas emoções, que deveriam ser cultivadas como fonte de prazer, envolvendo a unidade entre sexualidade e sentimento, e pressupondo a existência de um "eu interior" capaz de se expandir para incluir o outro (Costa, 1998). Para Chaves (2004), a tônica do amor romântico traz a ideia de uma relação de reciprocidade do par quanto aos seus sentimentos, sendo a coincidência no dar e receber afeto e prazer o grande pilar do relacionamento amoroso.

Nos casamentos da classe média burguesa, a importância do amor foi mantida em segundo plano até a metade do século XIX, época em que se começa a questionar os casamentos estabelecidos primordialmente por "interesse" e tem início uma apropriação dos elementos do amor romântico, com o sentimento amoroso sendo colocado em destaque. Ao ser levado para o interior do casamento, o amor romântico o influencia, mas, em contrapartida, é modificado, passando por um processo de domesticação. Enquanto na lógica romântica o amor possuía um aspecto contestador, por romper com as convenções do amor burguês, incluindo a satisfação emocional e a sexualidade nas relações amorosas, o amor romântico domesticado 
se moldava em função da necessidade de se manter a coesão da família, através do casamento eterno, visto como "destino pessoal e fonte de felicidade” (Chaves, 2004, p. 102).

A virtualidade da escolha do parceiro marca não só o exercício de uma maior liberdade, como representa a possibilidade de realização da satisfação emocional e sexual no encontro com o outro. Contudo, é importante frisar que, apesar de o amor romântico abarcar a sexualidade, ele se distancia dela como uma expressão puramente fervorosa, no sentido de uma compulsão sexual/erótica. Este tipo de amor é retratado por Giddens (1993) como amor-paixão, marcado por um encantamento pelo outro e por um alto investimento no objeto amoroso, o que levaria o indivíduo a um estado forte o suficiente para desviá-lo de outras relações e de suas obrigações cotidianas, devido à urgência de satisfação. Neste ponto, o autor estabelece uma diferença entre o amor-paixão - tido como "um fenômeno mais ou menos universal” (Giddens, 1993, p. 48), observado em culturas distintas e, ao mesmo tempo, refratário aos casamentos, por sua instabilidade - e o amor romântico, mais culturalmente situado, englobando os elementos do amor-paixão, porém dele se distinguindo pela predominância do aspecto sublime sobre o ardor sexual. É sob este aspecto que a virtude ganha um novo sentido. Se, até então, ela era vista, predominantemente, em ligação com as ideias de inocência e de castidade, agora passa a se referir também a uma qualidade de caráter, que servirá para diferenciar o parceiro como um ser especial. Este seria escolhido entre aqueles que, por suas características peculiares, seria capaz de tornar a vida do outro inteira, num sentido de plenitude e de complementaridade.

O que acontece é que acompanhando a ascendência da racionalidade moderna, o amor é reordenado, no casamento, com vistas ao controle e à organização da sociedade. Neste âmbito, ele se transforma em uma parceria para a vida, tendo como base a idealização do outro, o apoio mútuo e, sobretudo, a projeção de um desenvolvimento futuro (Giddens, 1993). Configura-se aí um amor apaziguado, que ganha um sentido de manutenção de um modo de vida, o que também contribui na tipificação de papéis de gênero: o homem é tomado como o provedor da família; e a mulher apresenta-se como a figura maternal e cuidadosa, submissa à autoridade do marido e responsável pela casa e pelos filhos (Costa, 1999). O amor se convertia em uma forma de segurança psicológica, por representar um porto seguro frente às dificuldades impostas por uma realidade objetiva e impessoal, vivida fora do lar (Chaves, 2004; Giddens, 1993). O amor, portanto, ao ser pensado neste contexto, distancia-se tanto do amor romântico, ligado ao Romantismo, em seu estado de experimentação e subversão, quanto do amor-paixão, uma vez que intensidade e imediatismo são vistos como elementos inconciliáveis com a proposta do "para sempre" (Chaves, 2004).

Disto pode-se apreender que a ideia de felicidade atrelada ao casamento está associada às noções de segurança e estabilidade, firmadas a partir da valorização das relações no âmbito privado, em concomitância com a possibilidade de realização pessoal através da vivência do amor, da sexualidade e da liberdade individual. Isso explica o lugar de destaque que o amor romântico passou a ter a partir da segunda metade do século XIX, com repercussões até os dias de hoje (Chaves, 2004).

No presente, segundo a visão de Costa (1998), o amor ganhou dimensão e sentido diferentes. Se antes ele era visto como um meio de alcançar a felicidade estritamente vinculado à família, hoje se prescinde de intermediários. O amor, como via de realização, torna-se, por si só, um "ideal de felicidade pessoal", tendo seu valor, portanto, "hiperinflacionado" (p. 19-20). Sem o suporte da família e de outros aparatos sociais fornecedores de identidade, como a política e a religião, observa-se um retraimento do indivíduo para as relações privadas, com uma consequente exaltação das expectativas amorosas e a busca de identidade concentrada neste campo. É nas relações amorosas que o indivíduo irá depositar uma parcela significativa de investimentos, buscando nelas uma resposta aos seus anseios emocionais, sexuais, afetivos e materiais. Neste compromisso íntimo, o indivíduo busca ainda assumir uma certa identidade, a partir da sua identificação como cônjuge ou companheiro de alguém, e da proximidade promovida pelo relacionamento que se instaura.

Surge, então, uma grande questão, ao considerarmos que, em termos históricos, o amor nasceu na era dos "sentimentos", das narrativas imaginadas e hoje estamos vivendo na era da incerteza, das emoções rápidas, bem ao ritmo de nossa sociedade de consumo. O fato é que permanecemos sonhando e clamando por um amor "imortal", mas as relações se apresentam com um prazo de validade. Eis a contradição da Pósmodernidade.

Ao levarmos em conta que as ideologias relacionadas às concepções de amor são atravessadas e acompanham os acontecimentos históricos, culturais e sociais, conforme tentamos mostrar aqui, entendemos que o amor romântico de hoje não é o mesmo do século XIX. As regras e normas rígidas que orientavam ou restringiam as práticas amorosas foram perdendo força, dando lugar a uma pluralidade que não favorece a adoção de uma única forma de pensar o amor ou conceber a conjugalidade. Chaves (2004) afirma que o amor romântico como ideário, embora representativo, não somente apresenta variações como convive simultaneamente com formas relacionais distintas. Nas palavras da autora (2004), "Algumas concepções de amor foram postas de lado, como por exemplo, o amor burguês; outras continuam vivas no imaginário e nas vivências do indivíduo, como o amor-paixão; outras, ainda, como o amor romântico, foram re-configuradas." (p.118).

O ideário romântico, contudo, não aparece sozinho, sendo acompanhado por valores e comportamentos relativos à igualdade, à liberdade e à individualidade, que surgem em seguida. Este campo misto, além de evidenciar a contradição própria da Pós-modernidade, retrata uma tentativa dos casais em "conciliar desejos, comportamentos e valores hierárquicos e igualitários, holísticos e individualistas, num processo de resignificação dos arranjos conjugais que rompe com a dualidade 'tradicional' versus 'moderno'." (Goldenberg, 2003, p. 10), aproximando-se, neste ponto, da ideia de Chaves (2004) sobre a atual multiplicidade do ideário amoroso. A este cenário também se aplica o conceito de customização, pressupondo 
a apropriação de diferentes valores e concepções - "novos" e "antigos" - como uma forma particular da experiência conjugal e amorosa. Vejamos a seguir como estes elementos se combinam nos achados de campo.

\section{Método}

Este trabalho é pautado em uma pesquisa qualitativa, para a qual utilizamos o método da história de vida tópica, que permite a emergência de fatos a respeito de uma determinada experiência, no caso, a vivência da conjugalidade, através da abordagem de temas específicos relacionados ao assunto. A utilização deste método revelou-se como possibilidade de obter um material rico para análise, por permitir aos entrevistados interpretar de maneira retrospectiva suas experiências, revivendo de forma crítica aspectos de sua história (Gomes, 2012).

\section{Participantes}

Foram realizadas entrevistas com casais compostos por pessoas com idades entre 28 e 30 anos, sem filhos, que coabitavam e mantinham uma relação há pelo menos dois anos. Definimos a faixa etária buscando atingir pessoas nascidas em contexto pós-moderno e que vivenciaram suas vicissitudes de modo mais direto. A escolha por casais sem filhos se deveu ao fato de termos como foco a conjugalidade e entendermos que, ao incluir filhos, outras situações seriam suscitadas, provavelmente remetendo a questões ligadas mais à família.

Foram entrevistados um casal homossexual feminino e um casal heterossexual, ambos pertencentes às camadas médias de Belo Horizonte - MG. A opção por trabalhar com pessoas das camadas médias se justifica por estas terem recebido de maneira mais incisiva as influências da Pós-modernidade e por terem sido as primeiras a buscarem alternativas fora dos padrões institucionalizados de relacionamento (Goldenberg, 2003). É importante ressaltar que não nos pautamos em uma proposta que visasse categorizar o casal homossexual e heterossexual de forma dicotômica. E, embora, por vezes, os discursos apresentados pelos sujeitos tenham remetido à ideia de um casal que mais se enquadra em normas tradicionais e a de um casal que se distancia destes padrões, nosso objetivo não foi o de classificá-los numa relação de oposição de forma tipificada, mas, sim, retratar e analisar formações distintas de conjugalidade.

\section{Instrumento}

Como instrumento para a coleta dos dados, utilizamos um roteiro de entrevista semiestruturada, elaborado de maneira que as expectativas sobre uma relação amorosa; a vivência da intimidade e da sexualidade; os significados da relação e do parceiro; os acordos e trocas no cotidiano, e a administração de conflitos próprios de cada relacionamento pudessem fornecer o material para análise posterior, entre outros tópicos, dos ideais de amor, que será alvo deste artigo.

\section{Procedimentos}

Coleta de dados. Para a captação dos sujeitos foi elaborado e enviado um informativo de divulgação aos contatos da pesquisadora, via e-mail. Com o mesmo intuito, foi criado um "evento" na rede social Facebook. Dentre aqueles com os quais se estabeleceu algum contato por estes meios, nenhum, efetivamente, prontificou-se a se submeter à entrevista. Os sujeitos entrevistados, então, foram indicados por pessoas próximas da pesquisadora, que mediaram a primeira comunicação. A abordagem inicial foi feita por e-mail. Em seguida, agendavam-se as entrevistas, que aconteceram nas residências dos sujeitos, conforme a sua conveniência. Os casais foram entrevistados primeiramente em conjunto e depois individualmente, a fim de se poder melhor compreender a experiência de cada um e observar possíveis diferenças nos discursos.

Os entrevistados assinaram o Termo de Consentimento Livre e Esclarecido, e a pesquisa foi aprovada pelo Comitê de Ética em Pesquisa da PUC Minas, sob o registro de $n^{\circ}$ 0051.0.213.000-1. Para preservar a identidade dos sujeitos, foram utilizados nomes fictícios, escolhidos aleatoriamente pela pesquisadora.

Análise de dados. Para o tratamento das informações, utilizamos a análise de conteúdo, por possibilitar uma leitura que vai além de uma mera reprodução do discurso dos sujeitos. Segundo Chizzotti (2003), o objetivo da análise de conteúdo é compreender criticamente o sentido das comunicações, decodificando-o, para assim apreender o conteúdo tanto explícito quanto implícito nas narrativas. As fases da análise de conteúdo organizam-se em torno de três polos, conforme Bardin (2009): pré-análise; exploração do material; e, tratamento dos resultados: a inferência e a interpretação. O princípio da análise de conteúdo é definido na demonstração da estrutura e dos elementos desse conteúdo para esclarecer diferentes características e extrair sua significação.

Após extraído o material do trabalho de campo, as falas dos entrevistados foram transcritas e agrupadas em temas, levando-se em conta o que era mais relevante de acordo com o objetivo do trabalho e, posteriormente, transformados em categorias de análise.

\section{Resultados e discussão}

Como forma de distinguir os casais e facilitar a leitura, os parceiros receberam a mesma letra inicial. O casal homossexual feminino recebeu nomes com a inicial C (Cátia e Cristina) e o casal heterossexual, com a letra $S$ (Sandro e Silvia). Cátia tem 30 anos, é formada em Desenho Industrial e trabalha ministrando aulas de animação e como autônoma em sua área. Cristina tem 29 anos, estuda Ciências Sociais e trabalha como Produtora Cultural.

Anterior à época em que estabeleceram a relação, Cátia namorou Dênis por quase três anos e se envolveu com Paula por cinco meses. Cristina foi casada com Marcos, com quem manteve 
uma relação de sete anos. Nos dois últimos anos casaram-se no civil e não tiveram filhos. Eles ainda não se separaram judicialmente. Cristina já havia "ficado com menina" antes de seu relacionamento com Marcos, mas como uma experiência pontual.

Cristina é natural de São Paulo e mudou-se para Belo Horizonte para ficar perto da namorada, no final de 2008. Retornou a São Paulo por não conseguir trabalho. Nesta ocasião, voltou a morar com o ex-marido numa relação de amizade. Voltou a Belo Horizonte no início de 2010, moraram em casas separadas e dividiram espaço com outras pessoas. Namoravam há dois anos e nove meses, até a data da entrevista (junho de 2011). Desde dezembro de 2010 montaram uma casa na qual vivem somente as duas.

Sandro tem 29 anos, é formado em Administração e trabalha na área de compras em uma empresa no ramo de aviação. Silvia tem 28 anos, é fonoaudióloga, trabalha em um hospital e presta serviço em clínicas particulares.

O casal se conheceu por intermédio da irmã de Silvia e de seu cunhado. Todos faziam parte do mesmo grupo da igreja que a família de Silvia frequenta. Sandro é natural de uma cidade do interior do Espírito Santo e mudou-se para Belo Horizonte há oito anos para cursar a faculdade. O casal relata que começaram "ficando" e em julho de 2005, oficializaram o namoro. Noivaram em 2010 e se casaram um ano e meio mais tarde, no religioso e no civil. Estavam casados há pouco mais de cinco meses, até a data da entrevista (março/2012).

Pretendemos analisar como se operam as variações quanto às concepções de amor presentes nas relações dos dois casais entrevistados Para Silvia, a relação amorosa é pensada como algo permanente, projetada para durar por toda uma vida, a ser compartilhada com alguém em quem confia para dividir as dificuldades e os momentos de alegria. Isto fica explícito no seguinte relato: "[...] a relação amorosa que é uma relação que dure pra sempre, tipo assim [...] que eu tenha um companheiro pro resto da minha vida, sabe, uma pessoa que eu possa contar pra sempre..."

O marido, neste lugar, ganha uma importância que tende a se intensificar com o tempo de convivência. A ideia é a de uma parceria que vai se estreitando até não haver uma diferenciação, num processo de fusão e transformação do eu e do tu em "a gente":

Uai, o significado que ele tem pra mim? [...] quanto mais tempo que você tá ali com a pessoa, mais isso vai acontecendo, a pessoa vira uma parte de você de certa forma [...] ele pra mim já é... um pedaço meu, assim, sabe? (Silvia).

O casamento de Silvia e Sandro pode ser interpretado, nestes termos, como a união de companheiros com uma ligação tão profunda e intensa que passam a serem pensados como duas partes de uma mesma unidade (MacFarlane, 1990). A noção de completude é reafirmada por Sandro, que nos dá a ideia de experimentar uma harmonia no convívio entre as demandas individuais e as solicitações como casal, o que se evidencia em sua resposta sobre o ideal de relação: "[...] eu acho que é isso, que eu encontrei a pessoa que eu consigo dividir minha maneira de ser com as minhas vontades, ela com as delas também, e a gente equilibrando e tocando a vida". Trata-se de um equilíbrio que se reflete também em sua concepção da relação amorosa, tida como uma combinação favorável devido às semelhanças que o par possui no que tange à criação e aos princípios de cada um:

Ah, eu acho que uma relação amorosa, tipo assim, é uma relação de muita afinidade, [...]. Saber respeitar, saber entender o lado do outro, como que o outro teve de criação, como que o outro pensa, como que pode ter esse equilíbrio, entendeu, eu acho que é isso que forma mais essa relação amorosa (Sandro).

Deste modo, para Sandro, a esposa é vista como aquela com quem ele se identificou, o que lhe garante uma qualidade peculiar, como a mulher em quem ele acredita e se ancora para construir uma base para o futuro: "Aí é... ela é minha base, a única pessoa que posso contar, tipo assim, é essa pessoa que eu tenho que conversar e abrir, falar dos meus problemas [...], então, tipo assim, abracei mesmo como ela sendo minha sustentação."

Vale ressaltar que, para Sandro e Silvia, o outro, como um "ser especial", não se faz notar por uma emoção explícita, mas, sim, pela atribuição de certas virtudes, em particular, aquelas ligadas ao respeito e à noção de família, que evocam uma exclusividade de um para o outro. Ao responder sobre o momento em que concluiu que Silvia seria a mulher para ele, o entrevistado reforça essa constatação: "Eu acho que, eu não sei te falar: 'não, aconteceu isso', [...] não foi: 'isso mudou tudo', não, não, foi aos pouquinhos. Um puxando, um conquistando um pouquinho o outro, mostrando assim os valores de cada um." Ainda que afetos vinculados a um estado de apaixonamento não fiquem evidentes, o lugar de cada um é marcadamente diferenciado no discurso do casal pelo modo como transitam em espaços privilegiados um do outro, em um movimento de abertura e cumplicidade.

O que nos parece é que a forma como este casal se relaciona se aproxima da ideia de amor domesticado (Chaves, 2004), assim como do conceito de amor-companheiro (Jablonski, 1991). De acordo com o segundo autor, o amor é vivido em estágios, sendo o primeiro deles o amor-paixão. Para Jablonski (1991), que converge com outros aqui mencionados, neste ponto, o amor-paixão se define como aquele em que o outro é supervalorizado, em meio à eclosão de um grande desejo de compartilhar emoções e experiências íntimas, acompanhado por um forte magnetismo sexual. Esta fase, no entanto, gradativamente, tende a ceder lugar a sentimentos menos arrebatadores, como a ternura, a amizade, o companheirismo. Nota-se, então, um arrefecimento da paixão, em concomitância com a consolidação de outros tipos de afetos. No discurso de Sandro e Silvia, observa-se um amor de expectativas mais sensatas do que aquelas que acompanham o amor-paixão, com todo o seu encantamento, o que pressupõe uma maior reflexividade, mesmo no início da relação.

Se, neste primeiro casal, alguns elementos fortemente disseminados do amor romântico, como o "para sempre" e a ideia de "completude", estão presentes e aparecem de forma muito nítida, o mesmo não ocorre com o casal formado por Cátia e Cristina. 
Assim responde Cátia sobre como definiria a relação com a namorada ${ }^{3}$ :

Olha, eu penso que a Cristina... eu não posso falar é o amor da minha vida, porque para eu entender que ela é um grande amor eu tive outros amores, então eu entendo que a Cristina é a pessoa que eu tenho que tá agora. A Cristina é uma pessoa que eu amo demais, demais. Eu tenho muita vontade dela, muita vontade de beijar, muita vontade de estar junto e é a pessoa que eu quero [...].

Cristina classifica a relação com a parceira como algo que "faz bem... primeiro porque é gostoso, é prazeroso tá junto [...]." Sobre seu sentimento, relata: "Eu tô numa fase bastante apaixonada. Eu tô achando a Cátia muito legal."

Os termos utilizados por elas, nestas falas, remetem a algo que mantém a relação viva e acesa, até mesmo para além da fase inicial de encantamento. Tem-se uma relação em que o prazer de estar junto ganha destaque e o desejo pelo outro serve como uma forma de impulsionar aquilo que elas almejam construir juntas, ainda que isso contenha algo de circunstancial, passível de sofrer mudança. Isso ocorre uma vez que o tempo vivido da relação é o presente, que marca os discursos de Cátia e Cristina, tanto no que diz respeito a projetos, quanto no que tange ao afeto experimentado no relacionamento.

Para Bauman (2004), as relações na contemporaneidade são marcadas pelo imediatismo, alinhadas a uma cultura consumista, que toma a união como um produto perecível, o qual precisa ser usufruído em tempo hábil para depois ser descartado. Assim é que as experiências instantâneas, resumidas na forte intensidade vivenciada no início do relacionamento amoroso, tornam-se mais convidativas do que as relações que implicam um esforço prolongado. O amor parece se dissociar do ideário romântico, manifesto na expressão "até que a morte os separe", para se tornar um episódio forte e de curta duração, dando margem a estados recorrentes de apaixonamento. Neste contexto, torna-se cada vez maior

[...] o número de pessoas que tendem a chamar de amor mais de uma de suas experiências de vida, que não garantiriam que o amor que atualmente vivenciam é o último e que têm a expectativa de viver outras experiências como essa no futuro (Bauman, 2004, p. 10)

É o que vimos acima no discurso de Cátia. No âmbito da experiência deste casal, os projetos pessoais de cada uma, com os quais se identificaram mutuamente no início da relação e que se tornaram planos em comum, são relatados como objetivos de curto e médio prazos:

Eu não tenho um pensamento a longo prazo. Eu penso em cinco anos pra frente, eu falei em cinco não sei porque, só não para ser três. O plano mais a longo prazo que a gente tem é viajar pra Berlim, eu falei que em 2012. [...]. A gente não combinou de ficar junto pra sempre. (Cátia)

Em entrevista individual, Cristina endossa este posicionamento:

Pois é, eu acho um pouco difícil fazer planos assim a longo prazo. Mas eu acho, ao mesmo tempo, que a gente tá construindo uma coisa legal. E aí, por mais que não tenha planos, assim, tipo, a gente tem planos até o fim do ano que vem. Mas, eu acho que é natural, eles vão surgindo. Acho que mais do que isso fica muito inalcançável.
O modo como se trata a questão da durabilidade, recorrente nos discursos das entrevistadas, remete ao conceito de amor confluente, de Giddens (1993), cujo princípio é o descarte da garantia de se ter um relacionamento infinito e único. Comparando-o ao amor romântico, define este amor confluente como ativo e contingente. O que está em primeiro plano, em relações que funcionam segundo esta lógica, não é a pessoa especial, mas a relação em si, que é vista como especial. Ambos os parceiros investem e desenvolvem a intimidade à medida que se sentem beneficiados e preparados para atender as demandas do outro (Giddens, 1993). Diferentemente do amor romântico domesticado (Chaves, 2004), aqui, a realização do prazer sexual mútuo é trazida para o centro da questão.

Para Cátia e Cristina, a relação, em si mesma, é o motivo da união. Bem em acordo com a dinâmica do amor confluente, não há, entre elas, a promessa de um compromisso permanente, a tônica parecendo ser a de demandas individuais que encontraram lugar para serem vivenciadas na relação, em um determinado momento, permeadas pelo desejo e por uma vivência da sexualidade entendida como satisfatória pelo par.

Giddens (1993), entretanto, aponta uma contradição importante neste tipo de amor: o que torna possível uma experiência compartilhada é o investimento que se faz na relação, ou seja, o compromisso que se estabelece, o qual, geralmente, contém a ideia de continuidade, ligada à expectativa de que o relacionamento dê provas de sua capacidade de longa duração. $\mathrm{O}$ contraste ocorre justamente porque o investimento, orientado para reforçar e estreitar o compromisso, parece mais arriscado, nos dias de hoje, quando se ressalta a sempre iminente possibilidade de a relação se dissolver. No caso analisado, a expectativa se concentra no presente. Por mais que haja confirmações processadas no cotidiano de que a relação existe, ela não é permeada pela ideia de um compromisso duradouro. Aqui, então, convivem, de certo modo, em contradição, o investimento e a intimidade entre as parceiras, de um lado, e a ausência da ideia de continuidade da relação a longo prazo, de outro.

Cristina, deixando uma estrutura de vida que tinha em São Paulo, toma a decisão de mudar para Belo Horizonte para ficar mais próxima da namorada, o que demonstra como a relação ocupa uma dimensão bastante significativa em sua vida, em dado momento: "É, logo que eu vim pra cá ocupava um espaço gigante, assim, era a vida inteira, porque eu saí de São Paulo, deixei meus amigos, minha família, tudo lá, e agora tá tomando um espaço devido, né?". Em outro momento da entrevista, ao falar do significado da relação, ela completa: "[...] um espaço grande, mas que convive com outras coisas. Então, se tirar, vai ficar um espaço vazio, mas as outras coisas acontecem." Notase, aí, que há esforços direcionados à relação, um investimento que lhe dá um certo sentido, o qual, todavia, não se projeta sobre todos os aspectos da sua vida.

Diante da mesma pergunta, a respeito do significado da relação, Cátia responde sobre o lugar que a parceira ocupa em sua vida, como ela a percebe, o que também denota uma ideia de ligação, de uma proximidade que vai sendo construída no relacionamento: "Ela é minha companheira, [...], ela tá integrada em todos os aspectos da minha vida. [...]. Uma construção 
juntas, eu enxergo essa relação assim, eu enxergo um companheirismo mesmo".

A ideia de construção está sempre presente no discurso de Cátia. Sobre este aspecto, é interessante lembrar que à medida que uma relação se edifica, as individualidades ali contidas vão sofrendo seus efeitos. Magalhães (2003) considera a conjugalidade como um campo de possibilidades de reestruturação das subjetividades que a compõem. Operando como um lugar de transformação do "eu dentro do nós", a conjugalidade se revela como um efeito que se volta para os parceiros de maneira individual. A cena conjugal é marcada por um jogo dinâmico inconsciente entre os parceiros, o qual origina uma estrutura organizadora própria do casal. Aquilo que se processa na relação exerce uma influência estruturante ou desestruturante nos cônjuges.

Cátia se surpreende com as transformações que ocorrem consigo mesma e com Cristina, percebendo como isso é revertido de maneira favorável para a relação, o que reforça a ideia de que o espaço conjugal oferece possibilidades de crescimento e evolução pessoal. Quando perguntada sobre os caminhos da relação, a entrevistada responde:

Vejo, vejo, vejo mudanças absurdas em mim e nela. Em mim, eu cresci demais, demais, eu entendi muita coisa de relações passadas, eu entendi muita coisa de relação com outras pessoas. [...]. Na Cristina, eu vejo um crescimento absurdo... Antes eu não sabia que ela ia ser capaz de enfrentar todo mundo para essa relação dar certo.

As mudanças sentidas com o tempo de relação também aparecem nas falas do outro casal. Sandro veio para Belo Horizonte morar com o irmão, que logo se casou. Ele considera ter sido esta uma fase em que esteve "vivendo muito sozinho". A convivência com Silvia acaba promovendo uma quebra dessa solidão, fazendo com que se sentisse uma pessoa mais aberta: “[...] até o namoro com ela foi assim, [eu] dentro de casa, uma coisa mais fechada." Nota-se, ainda, a questão da responsabilidade que o casamento trouxe para a sua vida, como um amadurecimento que é bem vindo: "Para mim foi um divisor de águas, eu saí daquela coisa de moleque pra assumir uma responsabilidade, entendeu?". Silvia também relata o seu processo de crescimento: "Ai, eu me vejo uma pessoa... tipo, mais madura, que tem condição de encarar mais as coisas, os problemas [...]”.

O casamento, nesta perspectiva, pode ser pensado não somente como uma experiência que estimula o desenvolvimento pessoal, mas também como um espaço que fornece segurança e uma certa ordem que baliza as vidas dos sujeitos.

Para Bauman (2004), mesmo nos relacionamentos efêmeros de nossos tempos, em que vigora a lógica de "lucrar", obter gratificações na relação, mais do que a ideia de se doar ao outro, a segurança é uma questão bastante importante, tendo em vista a necessidade de amparo diante das situações difíceis e da solidão. Do mesmo modo, permanece importante a necessidade de compartilhar os momentos de satisfação. Esta dimensão significativa que a conjugalidade ocupa, na vida dos indivíduos, aparece nos discursos de ambos os casais. Com isso se observa que o casamento se mantém, em tempos pósmodernos, como um abrigo para o qual o indivíduo se volta esperando proteção e um norte diante de uma realidade instável (Costa, 1998).

Apesar de a união ser vista como um somatório das identidades e um pilar seguro para ambos os casais, a maneira diferente como os ideais de amor são pensados entre eles se torna evidente em um trecho extraído da entrevista conjunta de Cátia e Cristina:

Cristina: É mais do que a soma de um e um, eu acho.

Cátia: Ah, tá. É mais do que a soma de um e um, mas não é duas metades. "Ah, a gente se completa", sem essa viadagem. Acho que é isso, né? "Ah, a gente se completa, aí encontrei nessa pessoa o que eu queria", não. Eu não vou andando para ela, a gente não faz assim [olham uma para a outra] na relação. Parece que a gente faz assim, dá a mão, sabe? E vai para frente.

É possível dizer que Cátia e Cristina se percebem como estando juntas não porque são "a promessa" uma da outra, mas porque se escolheram como parceiras de jornada, sendo que esta não remete a um futuro distante, mas é pensado a curto e a médio prazos. Diferentemente do casal Silvia e Sandro, o cônjuge, ali, não é uma figura com quem se espera contar para toda uma vida, como acontece quando o ideário romântico prevalece (Giddens, 1993). Ainda assim, o casamento é visto como um incentivador e facilitador, oferecendo uma sensação de segurança, que é muito desejada. O outro é alguém com quem se divide os interesses, os quais irão ganhar novas feições na união, possibilitando, inclusive, retornos para as subjetividades. Isto, com efeito, observa-se nas duas relações em análise, ainda que, na primeira, formada por Silvia e Sandro, seja mais patente a necessidade que ambos os parceiros têm do outro para se sentirem integrados.

Não se pode dizer que Cristina e Cátia vivam um amor-paixão, visto que - apesar da vontade que demonstram em estarem juntas, de um desejo, inclusive, manifestado na prática da sexualidade - elas fundam a relação para além desta fase. Cátia nos aponta, em seu discurso, essa noção de transição atravessada pelo relacionamento, sem desmerecer ou anular o desejo que existe e possui seu valor, conforme já visto: “[...] tesão tem menos, mas é uma outra coisa que a gente colocou no lugar. A gente conversa muito e a gente se entende cada vez mais [...]". Cristina também acrescenta em seu discurso componentes do amor-companheiro (Jablonski, 1991) ao comparar a relação a seu ideal de amor: "Eu acho que tem que ter várias coisas além do amor. Tem que ter admiração, respeito e companheirismo."

Ainda que Cristina e Cátia neguem o ideário romântico, na sua forma mais estereotipada, o fato é que se apropriam de alguns de seus elementos-chave. Como sugerimos mais acima, é possível dizer que esta relação se aproxima da ideia de amor confluente de Giddens (1993), por trazer à tona a questão da associação entre a satisfação emocional e pessoal e a vivência em um relacionamento que não somente lida com a transitoriedade, como faz dela parte importante de si, o que é expresso nos objetivos que as parceiras traçam juntas e nas expectativas que evidenciam. 


\section{Considerações finais}

Como se pode notar das entrevistas que realizamos com os casais, desenham-se duas relações bastante díspares, o que, de certo modo, vai ao encontro da condição pós-moderna, no sentido da multiplicidade que dela faz parte. Importa salientar, entretanto, os pontos de interseção entre os dois relacionamentos. Em ambos, com efeito, valoriza-se a parceria, havendo investimento de sentido na relação, bem como a preservação de uma necessidade de pertença. Elementos que podemos associar aos motivos pelos quais os casais, ainda hoje, em um cenário que parece desfavorecer as uniões, persistem na intenção de estabelecerem vínculos, independentemente do modo como estes se configuram.

Observamos, com Silvia e Sandro, uma forma relacional em que os ideais de amor e as expectativas referentes ao parceiro e à relação se mostram de maneira mais homogênea, prevalecendo aí os elementos do amor romântico domesticado e os valores tradicionais presentes de forma mais marcada. Com Cátia e Cristina, por sua vez, vimos um casal em que se evidencia uma maior heterogeneidade de elementos que se combinam, com expectativas centradas em eventos de curto e médio prazos, sem que isto comprometa a carga de energia emocional e pessoal ali depositada. A análise deste casal nos mostra que, na Pós-modernidade, parece estar havendo uma dissociação entre, de um lado, a busca do sentir-se seguro, do ser especial e do investir em uma relação, e, do outro, a perspectiva de durabilidade, o que coloca em questão a ideia de que o tempo de duração de um relacionamento é o que garante a presença dos pontos mencionados. É isto o que nos leva a pensar que talvez estejamos nos adaptando a uma lógica individualista, sem necessariamente cairmos em relações vazias e pobres de investimento emocional.

A nosso ver, a combinação dos ideais e dos valores assumidos pelos casais em questão reflete não só a ideia de customização, pois cada casal assume um modo singular de se relacionar, como diz também de uma capacidade adaptativa em que queremos crer.

Outra questão que parece fazer sentido é que, ainda que existam pontos que favoreçam a sustentabilidade da relação, não há nada que garanta sua maior duração, o que significa que os relacionamentos findados não tenham que ser, necessariamente, caracterizados como um fracasso. Essa pesquisa aponta que na Pós-modernidade parece estar havendo uma dissociação entre a durabilidade, a busca por um parceiro em que se possa confiar e o investimento emocional e material nos relacionamentos, sem que isso seja, necessariamente, pensado a longo prazo. Vemos sinalizada a possibilidade de estarmos avançando no sentido de considerar como satisfatórias as relações através de outros parâmetros que não seja apenas a durabilidade. Portanto, talvez a melhor pergunta que devemos nos fazer não seja o que faz uma relação perdurar, mas sim, o que pode ser considerada uma relação que dá certo nos dias de hoje. E já ensaiando uma resposta, possamos dizer que seja aquela sentida como gratificante e produtiva para o casal, segundo o arranjo que é estabelecido por ele.

Tentamos mostrar neste trabalho que a customização - como efeito da diversidade pós-moderna - irá, gradativamente, na construção da relação, possibilitar aos casais encontrar uma forma singular de relacionamento que supomos levar a uma satisfação mútua. Ao que tudo indica, apesar destas relações continuarem sendo influenciadas em maior ou menor grau pelos padrões herdados e por uma ordem social vigente, no caso, a sociedade de consumo em que vivemos, entendemos ser possível, com o decorrer do tempo, o surgimento de novos referenciais, alinhados a concepções de conjugalidade que ainda serão gestadas, mais próximas de uma realidade que os casais possam sustentar.

\section{Referências}

Bardin, L. (2009). Análise de conteúdo. Lisboa, Portugal: Edições 70, LDA

Bauman, Z. (2004). Amor líquido: Sobre a fragilidade dos laços humanos. Rio de Janeiro: Jorge Zahar.

Butler, J. (2008). Problemas de gênero: Feminismo e subversão da identidade. Rio de Janeiro: Civilização Brasileira.

Chaves, J. C. (2004). Contextuais e pragmáticos: Os relacionamentos amorosos na Pós-modernidade (Tese de Doutorado). Universidade Federal do Rio de Janeiro, Rio de Janeiro. Recuperado de http://teses.ufrj.br/ip_d/ jacquelinecchaves.pdf.

Chizzotti, A. (2003). Pesquisa em ciências humanas e sociais. São Paulo: Cortez.

Costa, J. F. (1998). Sem fraude nem favor: Estudos sobre o amor romântico. Rio de Janeiro: Rocco.

Costa, J. F.(1999). Ordem médica e norma familiar. Rio de Janeiro: Graal.

Diniz Neto, O., \& Féres-Carneiro, T. (2005). Psicoterapia de casal na pósmodernidade: rupturas e possibilidades. Recuperado de http://www.scielo.brscielo.php?pid=S0103-166X2005000200003\&script=sciabstract\&tlng=pt.

Giddens, A. (1993). A transformação da intimidade: Sexualidade, amor \& erotismo nas sociedades modernas. São Paulo: UNESP.

Goldenberg, M. (2001). Sobre a invenção do casal. Recuperado de http://www. revispsi.uerj.br/v1n1/artigos/Artigo\%207\%20-\%20V1N1.pdf.

Goldenberg, M. (2003). Novas famílias nas camadas médias urbanas. Recuperado de http://miriangoldenberg.com.br/images/stories/pdf/conjugalidades. pdf.

Gomes, R. (2012). Análise e interpretação de dados de pesquisa qualitativa. In M. C. S. Minayo, S. F. Deslandes, \& R. Gomes (Orgs.), Pesquisa social: Teoria, método e criatividade (pp. 79-108). Petrópolis: Vozes.

Grossi, M. P., Uziel, A. P., \& Mello, L. (Orgs.). (2007). Conjugalidades, parentalidades e identidades lésbicas, gays e travestis. Rio de Janeiro: Garamond.

Jablonski, B. (1991). Até que a vida nos separe: A crise do casamento contemporâneo. Rio de Janeiro: Agir.

MacFarlane, A. (1990). História do casamento e do amor. São Paulo: Companhia das Letras.

Magalhães, A. S. (2003). Transmutando a individualidade na conjugalidade. In T. Féres-Carneiro (Org.), Família e casal: Arranjos e demandas contemporâneas (pp. 225-245). Rio de Janeiro: PUC-Rio.

Massaud, M. (2002). Romantismo. Dicionário de termos literários (11aㅡ ed.). São Paulo: Cultrix.

Matos, M. (2000). Reinvenções do vínculo amoroso: Cultura e identidade de gênero na modernidade tardia. Belo Horizonte: UFMG.

Simmel, G. (2006). Fragmento sobre o amor: Escritos póstumos. In G. Simmel (Org.), Filosofia do amor. São Paulo: Martins Fontes.

Stengel, M. (2004). Tradições, contradições, transformações: A família na ótica de pais de adolescentes (Tese de Doutorado não publicada). Universidade Estadual do Rio de Janeiro, Rio de Janeiro.

Vaitsman, J. (1994). Flexíveis e plurais: Identidade, casamento e família em circunstâncias Pós- modernas. Rio de Janeiro: Rocco. 
Notas.

1. Os termos "pós-moderno" e "pós-modernidade" são empregados por Vaitsman (1994), Diniz Neto \& Carneiro (2005), entre outros, ao se referirem ao tempo que compreende dos anos 1960 até aos dias atuais. Optamos por sua utilização neste trabalho, embora diferentes expressões possam ser usadas para tratar de acontecimentos do mesmo período.

2. O termo customizar possui uma raiz estrangeira, originando-se do inglês customized e significa "feito ou alterado de acordo com especificações, requisitos individuais". (Dicionário Priberam da Língua Portuguesa, 2012).

3. Ao longo da entrevista, Cátia e Cristina não definem um termo específico que as nomeie uma para outra: "Às vezes a gente se refere como namorada, às vezes fala que é casada." (Cátia). Optamos pela utilização do termo "namorada" por não terem estabelecido legalmente uma união.

Ana Nascimento de Amorim, Mestre em psicologia pela Pontifícia Universidade Católica de Minas Gerais - PUC Minas, é Professora no Centro Universitário Newton Paiva. Endereço para correspondência: Rua Litargírio 11/102 - Grajaú - Belo Horizonte - Minas Gerais - CEP: 30430-580. Telefones: (31) 8811-1533 e (31) 3643-0024 E-mail: ananamorim@hotmail.com

Márcia Stengel, Doutora em Ciências Sociais pela Universidade Estadual do Rio de Janeiro (UERJ) e Pósdoutora em Educação pela Universidade Federal de Minas Gerais (UFMG), é

Professora do Programa de Pós-graduação de Psicologia da Pontifícia Universidade Católica de Minas Gerais - PUC Minas. E-mail: marciastengel@gmail.com 